\title{
Modelling Human Locomotion to Inform Exercise Prescription for Osteoporosis
}

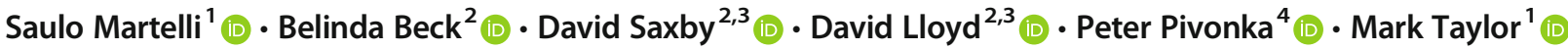

Published online: 25 April 2020

(C) The Author(s) 2020

\begin{abstract}
Purpose of Review We review the literature on hip fracture mechanics and models of hip strain during exercise to postulate the exercise regimen for best promoting hip strength.

Recent Findings The superior neck is a common location for hip fracture and a relevant exercise target for osteoporosis. Current modelling studies showed that fast walking and stair ambulation, but not necessarily running, optimally load the femoral neck and therefore theoretically would mitigate the natural age-related bone decline, being easily integrated into routine daily activity. High intensity jumps and hopping have been shown to promote anabolic response by inducing high strain in the superior anterior neck. Multidirectional exercises may cause beneficial non-habitual strain patterns across the entire femoral neck. Resistance knee flexion and hip extension exercises can induce high strain in the superior neck when performed using maximal resistance loadings in the average population.

Summary Exercise can stimulate an anabolic response of the femoral neck either by causing higher than normal bone strain over the entire hip region or by causing bending of the neck and localized strain in the superior cortex. Digital technologies have enabled studying interdependences between anatomy, bone distribution, exercise, strain and metabolism and may soon enable personalized prescription of exercise for optimal hip strength.
\end{abstract}

Keywords Hip strain $\cdot$ Physical exercise $\cdot$ Osteoporosis $\cdot$ Bone strength

This article is part of the Topical Collection on Nutrition, Exercise, and Lifestyle in Osteoporosis

Electronic supplementary material The online version of this article (https://doi.org/10.1007/s11914-020-00592-5) contains supplementary material, which is available to authorized users.

Saulo Martelli

saulo.martelli@flinders.edu.au

1 Medical Device Research Institute, College of Science and Engineering, Flinders University, Tonsley, SA 5042, Australia

2 School of Allied Health Sciences, Griffith University, Gold Coast, QLD, Australia

3 Griffith Centre of Biomedical and Rehabilitation Engineering (GCORE), Menzies Health Institute Queensland, Griffith University, Gold Coast, QLD, Australia

4 School of Chemistry, Physics and Mechanical Engineering Queensland University of Technology, Brisbane, Australia

\section{Introduction}

Reduced bone mass and compromised bone strength in osteoporosis are a major socio-economic burden. The health care cost for treating low and minimal energy fragility fractures was $\$ 2.8$ billion in Australia in 2012, and it is expected to rise to $\$ 3.8$ billion by 2022 due to population growth and ageing [1]; this figure is common to most regions of the developed world [2]. Physical exercise has long been proposed as a means for reducing the risk of fragility fracture by promoting bone accrual and improving motor function to reduce fall risk. However, the modest and variable bone response to exercise in adults complicates prescribing the type and amount of exercise for optimal bone health [3]. Modern digital technology can complement exercise prescription for osteoporosis by providing information about skeletal mechanics during locomotion.

A recent position statement endorsed by Exercise and Sport Science Australia (ESSA) summarized current research findings into specific guidelines for the prevention and 
management of osteoporosis through exercise [3]. In older adults, regular impact and high intensity resistance exercises may reduce the likelihood of both falling and fracture by enhancing musculoskeletal function and promoting modest bone accrual [3-7], yet the effect has been observed to be highly variable [8]. For example, in women over 58 years of age, percent change (mean $\pm \mathrm{SD}$ ) in femoral neck bone mineral density (BMD) in response to an 8-month training program including high intensity resistance and weight-bearing activities was $0.3 \pm 3.0 \%$ compared with $-2.0 \pm 3.0 \%$ in sedentary controls [6], thereby showing a variance larger than the mean effect (CV > 100\%). An understanding of the patterns of bone strain during different types of exercise together with longitudinal information on BMD may help optimize exercise programs to improve bone strength and mitigate the incidence of fragility fractures.

Digital technology can complement randomized controlled trial (RCT) designs by combining principles of mechanics, muscle and bone physiology with anatomical and functional measurements in participants into physicsbased models, which can provide information relating to musculoskeletal loading during exercise otherwise not accessible from direct human measures. For example, physics-based models are increasingly used in a variety of clinical contexts of increasing breath [9] such as studies of musculoskeletal function in healthy adults $[10 \bullet \cdot]$, obese children [11] and joint replacements [12]. Models provided muscle and joint forces $[10 \bullet \cdot, 13,14]$ and bone strain $[15,16]$ and improved prediction of bone strength and classification of fracture cases over traditional BMD measurements [17-19], motivating their integration into regulatory systems in the USA and Europe [20, 21]. In the context of exercise treatments for osteoporosis, current studies enabled quantifying the amount and distribution of hip strain for a variety of exercise types used for the prevention and management of osteoporosis $[3,10 \bullet \bullet$, 22-24]. Hence, physics-based models can inform exercise prescription for osteoporosis.

Here, we review the literature on models of skeletal mechanics for informing exercise prescription in osteoporosis. We focus on the hip, which shows the smallest and most variable response to exercise of the anatomical regions susceptible to osteoporotic fracture [6] and, when fractured, carries the most severe health consequences [2]. The exercise type required for maximizing hip strength is identified using the weakest link concept in relation to studies of hip architecture and fracture mechanics. Current studies providing hip strain during a variety of exercise types are reviewed and discussed in the context of exercise recommendations for osteoporosis by ESSA [3]. Finally, we provide the authors' perspective on the use of digital technology for enabling personalized prescription of exercise type and amount for optimal bone health.

\section{Exercise for Hip Strength}

Bone strength is determined by the weakest link in the structure in relation to the specific mechanical environment, geometry and loading. Hip architecture displays asymmetric trabecular organization and cortical thickness adapted to support habitual physical activity. The principal compressive trabecular network transfers the compressive load generated at the hip joint to the thick (3-4 mm) medial femoral neck cortex. The principal tensile trabecular network runs through the medial femoral head, the thin superior neck cortex $(<1 \mathrm{~mm})$ and the lateral greater trochanter, carrying the tensile load generated by bending of the neck. The structural asymmetry of the femur has been attributed to minimal loading in the superior neck cortex while walking due to the antagonist effect of the hip abductors, which generates compression for balancing the frontal plane moment, and the tension required to sustain the body weight [25]. The asymmetric structurally adapted hip displays approximately twice the strength under habitual loading compared with that associated with the impact from a sideways fall on the trochanter [26].

Age-related bone loss causes diffused bone weakening and increased susceptibility to fracture under minimal load in lowenergy falls, low dynamics events (e.g., stumbling) and spontaneously, for the weakest hips under intense muscle cocontraction [27]. Although a variety of fracture patterns have been observed, ranging from subcapital to subtrochanteric fractures, the thin superior neck cortex appears to represent the weakest link in the majority of fracture cases showing thinner superior neck cortices than non-fracture controls [28]. Laboratory experiments showed that the superior cortex opens in tension under habitual loading configuration [29] (Fig. 1) and crushes in compression while falling on the side (Fig. 2) in femurs of variable BMD [17], suggesting that osteoporosis affects strength but not the mode of failure of the hip. Therefore, it appears that promoting hip strength through exercise can be achieved by promoting either diffused bone accrual by increasing the strain intensity experienced during habitual activity or local thickening of the superior neck cortex by increasing bending of the neck. From an evolutionary perspective, promoting the thickening of the superior neck cortex through physical exercise means reversing the process of human evolution that made it thin [25].

\section{Classification of Studies of Hip Strain During Exercise}

At the time of writing, searching Medline and PubMed using keywords hip, strain, exercise and model yields 51 studies published over the past 10 years, of which 11 used integrated models for providing information pertaining to hip strain in humans for a variety of exercise types [10••, 22-24, 31-37]. 
Fig. 1 Cross-section images of a human femur (osteoporotic white women; age, 79 years; $T$-score $=$ -3 ) subjected to a single-leg stance configuration (red arrow) increased stepwise up to inducing a fracture opening in the superior sub-capital region of the neck. The figure displays the femur before load application (a) and after fracture occurred (b). Images were obtained using time-elapsed synchrotron-light microcomputed-tomography [30]
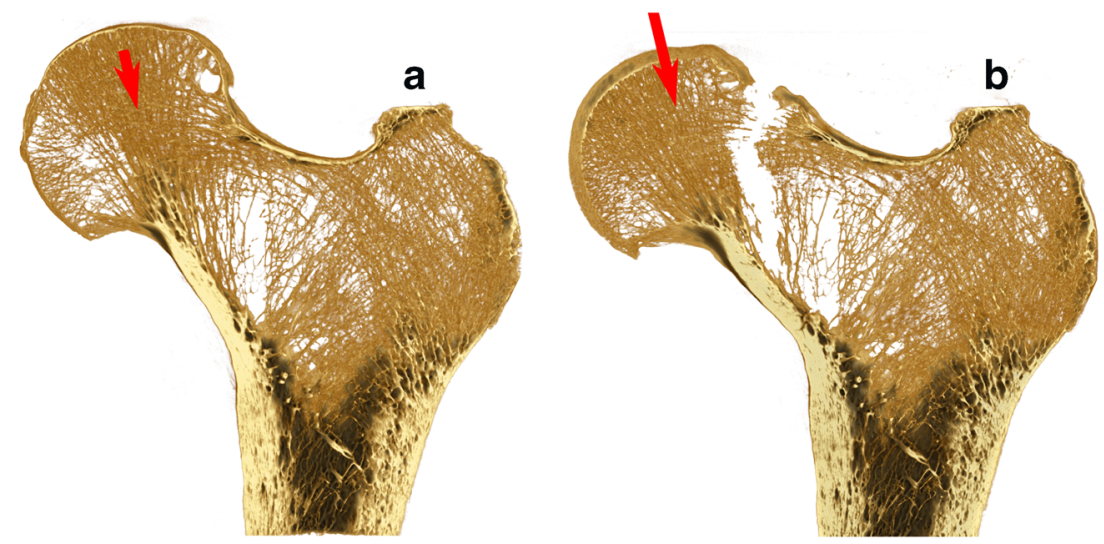

Integrated models combined musculoskeletal models of human motion providing muscle and joint forces during exercise $[38,39 \cdot 40]$ and structural models of femoral mechanics providing femoral strain under prescribed muscle and joint forces. Studies have focussed on normal activities $[10 \bullet, 22,31$, 33-37], impact and resistance exercises [10••, 22, 31, 36], age-related changes of hip mechanics during walking [37] and the effect of isolated hip-spanning muscle groups on hip mechanics [24]. Henceforth, such models are reviewed for providing guidance for designing exercise interventions targeting specific regions of the hip.

All the 11 studies analysed here assumed rigid skeletal and joint behaviour and optimal control assuming that muscles are recruited by targeting a prescribed function such as, for example, minimizing muscle activation or energy consumption. Optimal control was found to provide estimates of the hip contact force in agreement with published measurements [10••] and to exceed by less than $0.22 \mathrm{BW}$ the hip contact force while walking obtained by imposing the model to follow $\left(R^{2}=0.60\right)$ some electromyography recordings in participants [13]. However, optimal control methods have difficulty in tracking recorded antagonist muscle contraction, which can drive the hip contact force up by multiples of the body weight during exercises requiring joint stabilization like stumbling
[41] or reaction to unexpected motion perturbations [42]; these conditions were not considered by the studies analysed here. Regarding model anthropometry, most models scaled a generic body anthropometry to intersegmental lengths in participants, providing consistent cohort averages of the hip contact force $\left(R^{2}=0.81\right)$, femoral neck strain $\left(R^{2}=0.95\right.$; slope $=$ $0.96-0.97$ ) and a peak error equal to 4.2 BW [31]. Similarly, skin movements in common stereo-photogrammetry motion capture experiments were shown to provide consistent patterns and timing of the hip contact force but caused a variation of the force intensity equal to $1.8 \mathrm{BW}$ [43]. For comparison, the hip contact force during walking is $2.5-4.5 \mathrm{BW}$ [44] and over 9-12 BW can be expected in exercises for osteoporosis management generating 2-3 BW ground reaction force [3]. Therefore, the studies analysed here provided the main effect of exercise type while their validity in specific participants should be taken with caution.

Concerning the femur's structural model, some studies modelled femoral strain using bone geometry and distribution in calibrated computed tomography $(\mathrm{CT})$ images and a procedure validated earlier for calculating cortical strain $\left(R^{2}=0.89\right.$ $0.95,[15,16])$ and hip strength $\left(R^{2}=0.80-0.85 ;[17]\right)[10 \bullet$, $22-24,32,45]$. The same procedure was used to model a osteoporotic donor (white women; age, 81 years old; $T$ score $=$
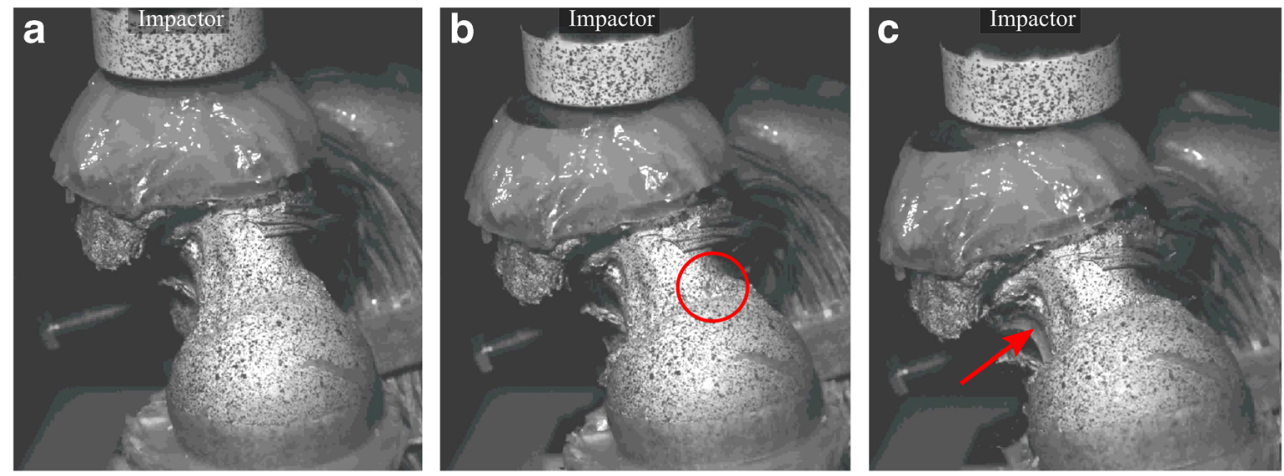

Fig. 2 Three subsequent frames obtained using high speed cameras (at $15,000 \mathrm{fps}$ ) displaying fracture in an osteoporotic donor (white woman; age, 66; $T$-score $=-2.09$ ) while replicating the impact resulting from a fall on a side (unpublished). Frames represent the femur before touchdown (a), at the time of the first cortical opening observed in the superior neck (b, red circle) and fracture progression to the medial neck (c, red arrow). Speckling and strain gauging seen in the images were part of a different study 
-2.5 ) combining body anatomy from full-body CT imaging and dissection and a structural model of the femur experimentally validated $\left(R^{2}=0.95\right)$ later used for studying different exercises [22]. Other studies fitted a generic bone density map to a cohort reporting limited information on model validity $[36,37]$. Therefore, it appears that validated models can be used to study the amount of strain under prescribed forces in participants while different technologies may enable ranking of exercise types. These differences should be considered when comparing different studies.

Models provided estimates of hip strain enabling ranking exercises consistently with their osteogenic capacity found in current randomized studies [46-49]. For example, 50 unilateral hops per day per 6 months caused $0.8-2.8 \%$ increase of femoral neck BMD in premenopausal women [46, 47] in agreement with higher strain while hopping and jumping over walking in all numerical studies analysed [10••, 22, 31, 36]. Squatting and deadlift exercises, as opposed to hip abduction exercises, caused concomitant strength increase of both the hip and the hip extensor muscles [48] in agreement with the ability of the hip extensor muscles, as opposed to the hip abductor muscles, to load the superior neck in our earlier numerical analyses [22-24]. Fast walking $(6 \mathrm{~km} / \mathrm{h})$ was found to nearly double strain, either in tension or compression, experienced by the superior neck during normal walking $(4 \mathrm{~km} / \mathrm{h})$ in agreement with earlier observation of diminished bone loss in a self-paced brisk walking exercise intervention [49]. Finally, the heterogeneity of the bone response to exercise observed by Lang and colleagues [48] is in agreement with the heterogeneity of hip strain reported by most numerical studies $[10 \bullet$, $22,32]$.

Regarding model consistency, comparison between models is complicated by the limited number of studies analysed here, different procedures used for modelling femoral mechanics, often incomplete information of exercise kinematic and dynamic and by different mechanical variables for assessment. For example, different studies used principal strain components [36], effective strain [10••], strain energy density per unit of bone mass [22] and strain averages over different bone volumes $[10 \bullet$, 37]. To date, there is no gold standard for comprehensive verification of modelled lower limb muscle forces, except at the triceps surae [50] and quadriceps [51, 52], and limited verification data for hip contact forces [53] and femoral strain [54]. One study compared the tensile strain in the proximal lateral shaft during walking to corresponding strain measurement published for two hip-snapping syndrome patients (i.e., 1198-1454 $\mu \varepsilon$ in tension and 393-948 $\mu \varepsilon$ in compression) [54], hence providing a low-strain point for model verification [31]. A different high strain point for model verification may be obtained, for example, by comparing the strain calculated during high intensity safe exercises to bone damage threshold levels $[22,55]$. We expect that the increase in the number of studies, the availability of benchmark data, open databases and cross-laboratory initiatives will soon promote consistency across and facilitate comparison between studies.

\section{Exercise Intensity and Type}

The osteogenic response to exercise occurs at locations where strains exceed those of habitual loading, with the latter typically considered during normal walking in sedentary individuals (speed, 3.5-4.5 km/h). As such, exercise generating higher strain in the superior neck cortex than that during normal walking is preferable for promoting hip strength. During walking, the effective strain in postmenopausal women, averaged over 12 neck portions, in the anterior and superior femoral neck is $1045-1241 \mu \varepsilon$ [10••]. Gait speed is a well-known indicator of age-related functional decline [56]. Although Lim et al. showed that muscle contribution to acceleration of the centre of mass is invariant to age [57], Anderson and Madigan [37] showed that young participants (age, $25 \pm 4$ years) display higher ground reaction (9\%), hip contact force (18\%) and similar strain levels during late stance as compared to older counterparts (age, $79 \pm 5$ years) walking at the same speed. Since hip strain increased as BMD decreases, hip strain may also be an indicator of functional decline, independent from gait speed [37].

Other common activities including stair ambulation, fast walking and light jump in place confirmed minimal loading of the superior neck cortex theorized earlier by Lovejoy for upright locomotion [25] and display similar strain patterns $[10 \bullet \bullet$. Nevertheless, stair ambulation was found to induce in the superior neck 30\% higher effective strain (1410-1639 $\mu \varepsilon)$ than walking, suggesting that stair ambulation may be a useful mechanical stimulus for the hip while ageing [10••]. Conversely, lower strain than walking was found during landing on both feet from a light jump in place generating 0.6 BW ground reaction force on each foot [10••]. In women aged over 60 years, the ground reaction force explained the $52-85 \%$ of the variance of the effective strain at mid-femoral neck [10••].

Higher intensity exercises including fast walking, hopping, jumping and resistance training exercises about the hip were ranked using estimates of hip contact force and strain [36]. Hopping and running at $7-9 \mathrm{~km} / \mathrm{h}$ generated the highest hip contact force (6-8 BW). Hopping generated about a threefold increase of the peak tensile strain in the inferior neck over every other exercise analysed and the highest compressive strain in the inferior neck. Fast walking $(6 \mathrm{~km} / \mathrm{h})$ generated the highest tensile strain in the superior neck, closely followed by running (7-9 km/h), and the highest compressive strain, closely followed by hopping. Fast walking, hopping (propulsion) and running $(9 \mathrm{~km} / \mathrm{h})$ induced $1.5-2.5$ times higher strain than normal walking, either in tension or compression, in the superior neck. Fast walking and running at an 
increasing speed $(5-9 \mathrm{~km} / \mathrm{h})$ caused similar strain levels in the superior neck, likely because of reduced muscle ability to generate support as speed increases [58]. All resistance exercises about the hip induced lower strain in the hip than normal walking. However, the hip torque generated during exercise was not provided. By pooling all the activities together, the hip contact force explained the $80 \%$ of the tensile strain variance in the superior neck. However, the strain variance explained by the ground reaction force decreased to $20 \%$ focusing on the 12 exercises generating higher hip contact force than normal walking (> 4 BW) (Fig. 3), complicating ranking of osteogenic activities using the hip contact force intensity and suggesting a specific effect of exercise type on the hip contact force direction.
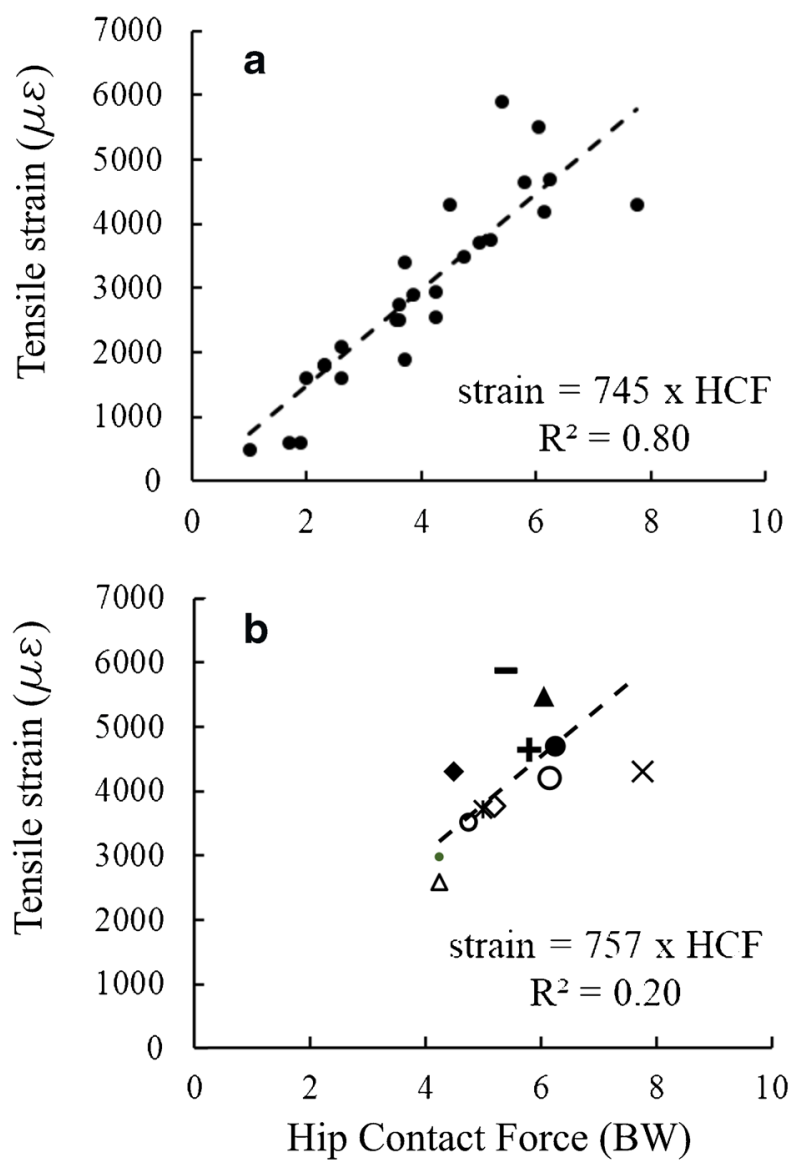
$\times$ Hopping (propulsion)
-Running@7 km/h
OHopping (landing)

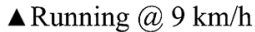
+Running@ $8 \mathrm{~km} / \mathrm{h}$
-Walking @ 6km/h (late stance)
$\diamond$ Running@6km/h
*Walking@6km/h (early stance)
oRunning@ $5 \mathrm{~km} / \mathrm{h}$
-Walking@ $5 \mathrm{~km} / \mathrm{h}$ (late stance)
-Walking@ $5 \mathrm{~km} / \mathrm{h}$ (early stance)

Fig. 3 Linear regression analysis between the tensile strain in the superior neck and the intensity of hip contact force for the exercises analysed by Pellikaan and colleagues [35]. The regression was performed by pooling all the exercises together (Fig. 3a) and for the exercises inducing a hip contact force higher than that generated by normal walking (Fig. 3b)
The specific strain and strain energy generated per unit of ground reaction force and joint torque were studied using the model of an osteoporotic donor combining body anatomy from full-body CT imaging and dissection and a structural model of the femur experimentally validated $\left(R^{2}=0.95\right)$ [22]. The model was animated by weight-bearing activities recorded in a young body-matched volunteer and maximal isokinetic contractions about the hip and knee in a mixed cohort aged 61-78 years [59]. Long jumps generating 0.62.6 BW ground reaction force and maximal hip extension exercises caused approximately $5000 \mu \varepsilon$ tension in the superior neck and highly heterogeneous strain maps showing focal strain varying from the superior (hip extension and knee flexion) to the anterior neck (long jump). The specific strain energy generated per unit ground reaction force in weightbearing exercises and per unit of joint torque in resistance training exercises varied by $2-10$ times across exercises. Differences in the specific strain and strain energy across exercise were then attributed to the specific muscle contractions driving each different exercise.

A study investigated the hip contact force orientation, intensity and hip strain potentially generated by each hipspanning muscle group and their relation to anatomy and body posture [24] (Fig. 4). The hip abductor muscles generate predominantly compression at $0^{\circ}$ hip abduction by pulling the greater trochanter toward the ilium and their forcegenerating capacity decreases as the hip abduction angle increases and loading of the neck becomes substantial bending at $40^{\circ}$ hip abduction. The hip extensors (gluteus maximus and hamstring muscles) compress the femur between the pelvis and the tibia, generating a hip contact force at a small angle from the diaphyseal axis and causing mostly bending to the neck and tension in the superior neck. The iliopsoas, the primary hip flexor muscle, pulls the femur from the lesser trochanter compressing the posterior neck and tensioning the anterior neck. Interestingly, the hip contact force during normal daily activities, as measured in patients wearing a telemetric hip implant [44], was found to span a narrow central position in the envelope of the hip loadings potentially generated by each muscle separately [23], thereby supporting the use of multiaxial exercises to cause extreme non-habitual loading to the hip. This information can be used for determining the exercise type targeting specific hip regions.

\section{Exercise Recommendations}

The exercise recommendations of the ESSA position statement include a mix of weight-bearing and resistance exercises of increasing intensity inducing from 2 to $3 \mathrm{BW}$ ground reaction force for the management of osteoporosis to above $4 \mathrm{BW}$ ground reaction forces for osteoporosis prevention [3]. Model results support ESSA's current exercise recommendations and 


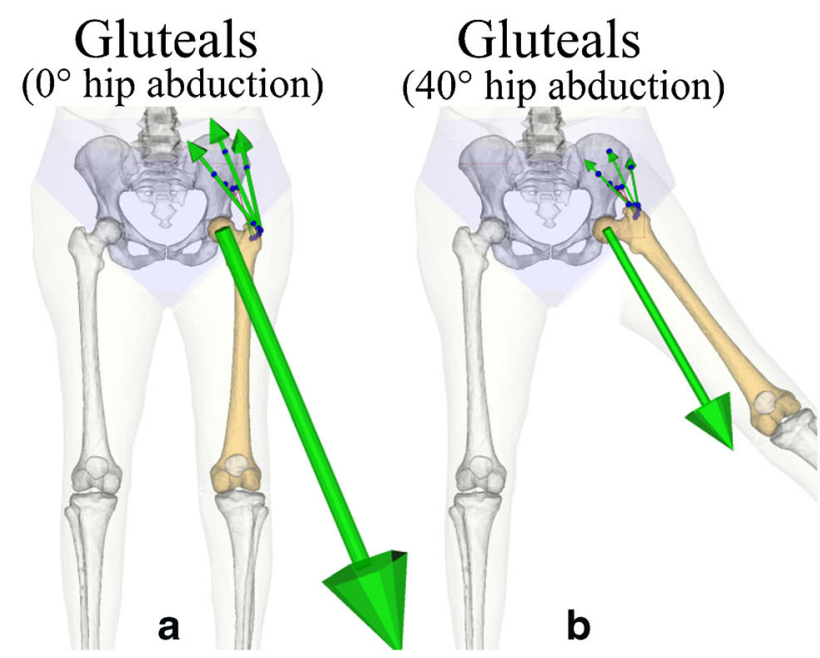

\section{Hamstring}

Fig. 4 The hip load generated by contractions of the gluteus (gluteus medius and minimus) and of the hamstring muscles. The gluteus generates a mostly compressive load to the femoral neck at $0^{\circ}$ hip abduction (a) and significant bending at $40^{\circ}$ hip abduction (b). The hamstring generates a hip contact force at small angles from the

provide information for optimizing current exercise treatments.

Fast walking $(6 \mathrm{~km} / \mathrm{h})$ and stair ambulation, not included in ESSA's recommendation, may be easily integrated into normal daily activity to help mitigate the natural age-related bone decline. Running is unlikely to translate into increased mechanical stimulus of the hip compared with fast walking. High intensity jumping and hopping exercises may promote anabolic response of the superior neck. Multidirectional exercises may leverage the different capability of different muscle groups and postures for loading above usual levels different hip regions. Resistance exercises targeting hamstring and hip extensor muscles, among those recommended by ESSA, have the highest potential for loading the superior neck cortex [22]. Concerning exercise safety, exercises generating 2-3 BW ground reaction force in osteoporotic patients were found safe in a single validated model [22]. No study reported the safety of different exercise types in osteoporosis for a broader range of BMD levels.

Models can also contribute to the design of questionnaires of self-reported physical activity for relating exercise regimens to hip response and for guiding exercise recommendations. For example, the bone-specific physical activity questionnaire (BPAQ) combined self-reported physical activity and an osteogenic index, which was based on information on the ground reaction force, loading rate, frequency and resting time $[60,61]$. Such questionnaire explained $65 \%$ of the variance of femoral neck BMD in young males [62, 63], improving the otherwise modest relationship of self-reported generic physical activity [64]. The specific strain and strain energy per unit of ground reaction force in the models can be used to weight exercises according to both their intensity (ground reaction force) and type (specific effect). diaphyseal axis causing substantial bending to the neck (c). Force vectors for the gluteus and the hamstring muscles are scaled differently to improve the readability of the figure. Animations representing the entire range of motion are available in the supplementary material

\section{A Perspective Toward Personalized Exercise Prescription}

Personalized exercise prescription requires discerning individual features of the hip response to exercise that may be determined by complex interaction between anatomy, muscle function, bone distribution and metabolism. Therefore, accounting for the interaction between all these features can enable personalized prescription of exercise treatments for osteoporosis. Here, we provide the authors' perspective toward personalized prescription of exercise-diet-drug treatments.

Significant progress has been made toward a fast, reliable and personalized physics-based model of human physiology. Current technologies can incorporate anatomical, mechanical, physiological and neurological features in each individual $[40,65]$. The body anatomy in the model can be informed by medical imaging [66-68] or extracted from population databases $[69,70]$. Statistical methods have been developed for improving the anatomical fidelity in the model using the limited set of information typically available in a clinical environment [71, 72]. Real-time or near real-time numerical methods have been developed to predict muscle and joint force [73], bone strains [74, 75] and strength [76]. Technologies have been developed to constrain the problem of muscle coordination to available observations of muscle activity [77, 78] and to reduce the bone position error in current motion capture technologies [79]. Similarly, bone anatomy and distribution can be obtained from calibrated CT images $[10 \bullet \cdot, 22,31]$ or extracted from population databases [76]. Access to high performance computing hardware, efficient new computational algorithms [74, 75, 80, 81] and open-source population databases [71] have reduced 
the burden of implementing robust models. These advances will enable personalized computational models of hip strength and strain during exercise.

Regarding the response of hip strength to exercise, recent evolutions of the mechanostat model proposed by H. Frost in 1983 describe how osteocytes and lining cells sense changes of the mechanical stimulus and adapt current bone structure by activating osteoblasts (i.e. bone-forming cells) and osteoclasts (i.e. bone-resorbing cells) [82-84] where the mechanical stimulus exceeds, or is lower, than its homeostatic value $[85,86]$. Typically based on animal studies [87-89], these models can be used for determining the amount of bone deposited, or resorbed, as a function of exercise, individual metabolism, diet and pharmacological treatment $[90,91 \bullet, 92]$ for different anatomical locations and bone types [87-89]. In humans, bone adaptation theory has been used to relate normal activity to bone distribution [86, 93], for studying the long-term stability of total hip replacements [94-98] and the hip response to legpress exercises [23]. However, most human studies focused only on the mechanical component of bone adaptation, but not metabolism [23, 86, 93-98]. Only one human study used models of bone metabolism focussing on changes of the mid-femoral diaphysis due to ageing, parathyroid hormone treatment and the lack of gravitational forces during space flights using a single representative mechanical loading [99]. Incorporation of models of hip metabolism and mechanics during exercise is the current focus of the bone research community.

In the coming years, it is likely to be possible to deploy a highly personalized computational model of hip strength and response to exercise with minimal imaging requirements in minutes, which can then be used to design the exercise regime for a given individual. The use of such models in combination with retrospective and longitudinal exercise interventions will allow appropriate identification of model assumptions and technology for personalized prescription of exercise type and amount for optimal hip strength.

\section{Conclusion}

The analysis of the current studies on hip strain during exercise has shown that fast walking and stair ambulation, but not necessarily running, may help mitigating the natural agerelated bone decline and may be easily integrated into routine daily activity. High intensity jumps and hopping promote hip strain in the superior neck higher than that during walking and multidirectional exercises may cause beneficial non-habitual strain patterns. Resistance knee flexion and hip extension exercises can induce high strain in the superior neck when performed using maximal resistance loadings in the average population. Information about exercise safety in the models analysed is marginal and at times contrasted likely due to limited model verification in some cases. Digital technologies can help study the interdependencies between anatomy, bone distribution, exercise, strain and metabolism thereby enabling personalized prescription exercise for optimal hip strength.

Funding Information This study is supported by the Australian Research Council (DP180103146; FT180100338).

\section{Compliance with ethical standards}

Conflict of interest All the authors declare no conflict of interest in relation to the present study.

Human and Animal Rights and Informed Consent This article doesnot contain any studies with human or animal subjects performed byany of the authors.

Open Access This article is licensed under a Creative Commons Attribution 4.0 International License, which permits use, sharing, adaptation, distribution and reproduction in any medium or format, as long as you give appropriate credit to the original author(s) and the source, provide a link to the Creative Commons licence, and indicate if changes were made. The images or other third party material in this article are included in the article's Creative Commons licence, unless indicated otherwise in a credit line to the material. If material is not included in the article's Creative Commons licence and your intended use is not permitted by statutory regulation or exceeds the permitted use, you will need to obtain permission directly from the copyright holder. To view a copy of this licence, visit http://creativecommons.org/licenses/by/4.0/.

\section{References}

Papers of particular interest, published recently, have been highlighted as:

- Of importance

•- Of major importance

1. Watts JJ, Abimanyi-Ochom J, Sanders KM. Osteoporosis costing all Australian: A new burden of disease analysis - 2012 to 2022. Osteoporos. Aust. 2013. Available from: http://dro.deakin.edu.au/ eserv/DU:30060270/wattsosteoporosiscoasting-2013.pdf

2. Cummings SR, Melton LJ. Epidemiology and outcomes of osteoporotic fractures. Lancet [Internet]. 2002;359:1761-7. Available from: http://www.ncbi.nlm.nih.gov/pubmed/12049882

3. Beck BR, Daly RM, Singh MAF, Taaffe DR. Exercise and Sports Science Australia (ESSA) position statement on exercise prescription for the prevention and management of osteoporosis. J Sci Med Sport [Internet]. Sports Medicine Australia; 2017;20:438-45. Available from: https://doi.org/10.1016/j.jsams.2016.10.001

4. Heinonen A, Sievänen H, Kyröläinen H, Perttunen J, Kannus P. Mineral mass, size, and estimated mechanical strength of triple jumpers' lower limb. Bone. 2001;29:279-85.

5. Multanen J, Nieminen MT, Häkkinen A, Kujala UM, Jämsä T, Kautiainen $\mathrm{H}$, et al. Effects of high-impact training on bone and articular cartilage: 12-month randomized controlled quantitative MRI study. J Bone Miner Res. 2014;29:192-201.

6. Watson SL, Weeks BK, Weis LJ, Harding AT, Horan SA, Beck BR. High-intensity resistance and impact training improves bone mineral density and physical function in postmenopausal women with 
osteopenia and osteoporosis: The liftmor randomized controlled trial. J Bone Miner Res. 2018;33:211-20.

7. Ma D, Wu L, He Z. Effects of walking on the preservation of bone mineral density in perimenopausal and postmenopausal women. Menopause [Internet]. 2013 [cited 2018 Oct 9];20:1216-26. Available from: http://content.wkhealth.com/linkback/openurl? sid=WKPTLP:landingpage \&an=00042192-201311000-00019

8. Martyn-St James M, Carroll S. A meta-analysis of impact exercise on postmenopausal bone loss: the case for mixed loading exercise programmes. Br J Sports Med [Internet]. 2009 [cited 2012 Feb 21];43:898-908. Available from: http://www.ncbi.nlm.nih.gov/ pubmed/18981037

9. Martelli S, Al-Dirini RMA, Van Sint Jan S. Medicine and virtual physiological human. In Sofia Scataglini, Gunther Paul editors. DHM posturography 1st ed. Academic Press; 2019. p. 577-89.

$10 . \bullet$ Kersh ME, Martelli S, Zebaze RMD, Seeman E, Pandy MG. Mechanical loading of the femoral neck in human locomotion. J Bones Miner Res [Internet]. United States; 2018 [cited 2019 Oct 8];33:1999-2006. Available from: http://www.ncbi.nlm.nih.gov/ pubmed/11706546?dopt=abstract\%5Cnpapers2://publication/ uuid/B242328A-8AB7-4A5F-A8E8-05DB2B0B67BE. This study provides the strain of the hip in postmenopausal women accounting for variation in bone geometry and distribution during common physical exercises.

11. Lerner ZF, Browning RC. Compressive and shear hip joint contact forces are affected by pediatric obesity during walking. J Biomech. 2016;49:1547-53.

12. Wesseling M, Meyer C, Corten K, Desloovere K, Jonkers I. Longitudinal joint loading in patients before and up to one year after unilateral total hip arthroplasty. Gait Posture. Elsevier B.V.; 2018;61:117-24.

13. Hoang HX, Pizzolato C, Diamond LE, Lloyd DG. Subject-specific calibration of neuromuscular parameters enables neuromusculoskeletal models to estimate physiologically plausible hip joint contact forces in healthy adults. J Biomech. 2018;80:11120.

14. Serrancoli G, Kinney AL, Fregly BJ, Font-Llagunes JM. Neuromusculoskeletal model calibration significantly affects predicted knee contact forces for walking. J Biomech Eng. 2016; https://doi.org/10.1115/1.4033673

15. Taddei F, Cristofolini L, Martelli S, Gill HS, Viceconti M. Subjectspecific finite element models of long bones: An in vitro evaluation of the overall accuracy. J Biomech [Internet]. Elsevier; 2006;39: 2457-67. Available from: https://doi.org/10.1016/j.jbiomech. 2005.07.018

16. Schileo E, Dall'ara E, Taddei F, Malandrino A, Schotkamp T, Baleani M, et al. An accurate estimation of bone density improves the accuracy of subject-specific finite element models. J Biomech. 2008;41:2483-91.

17. Dall'ara E, Luisier B, Schmidt R, Kainberger F, Zysset P, Pahr D. A nonlinear QCT-based finite element model validation study for the human femur tested in two configurations in vitro. Bone [Internet]. Elsevier Inc.; 2012 [cited 2012 Nov 22];52:27-38. Available from: http://www.ncbi.nlm.nih.gov/pubmed/22985891

18. Ruiz Wills C, Olivares AL, Tassani S, Ceresa M, Zimmer V, González Ballester MA, et al. 3D patient-specific finite element models of the proximal femur based on DXA towards the classification of fracture and non-fracture cases. Bone [Internet]. Elsevier; 2019 [cited 2019 Jun 5];121:89-99. Available from: https://www. sciencedirect.com/science/article/pii/S8756328219300018?via\% 3Dihub

19. Qasim M, Farinella G, Zhang J, Li X, Yang L, Eastell R, et al. Patient-specific finite element estimated femur strength as a predictor of the risk of hip fracture: the effect of methodological determinants. Osteoporos Int [Internet]. Springer London; 2016 [cited 2019
Mar 20];27:2815-22. Available from: http://link.springer.com/10. 1007/s00198-016-3597-4

20. Morrison TM, Pathmanathan P, Adwan M, Margerrison E. Advancing regulatory science with computational modeling for medical devices at the fda's office of science and engineering laboratories. Front Med. 2018; https://doi.org/10.3389/fmed.2018. 00241

21. Morrison TM, Dreher ML, Nagaraja S, Angelone LM, Kainz W. The role of computational modeling and simulation in the total product life cycle of peripheral vascular devices. J Med Devices, Trans ASME. American Society of Mechanical Engineers (ASME); 2017;11.

22. Martelli S, Kersh ME, Schache AG, Pandy MG. Strain energy in the femoral neck during exercise. J Biomech [Internet]. 2014 [cited 2014 Jun 4];47:1784-91. Available from: http://www.ncbi.nlm.nih. gov/pubmed/24746018

23. Martelli S, Mokhtarzadeh H, Pivonka P, Ebeling PR. The Femoral Neck Mechanoresponse to Hip Extensors Exercise: A Case Study. J Osteoporos. 2017; https://doi.org/10.1155/2017/5219541

24. Martelli S. Femoral Neck Strain during Maximal Contraction of Isolated Hip-Spanning Muscle Groups. Comput Math Methods Med. 2017; https://doi.org/10.1155/2017/2873789

25. Lovejoy CO. Evolution of human walking. Sci Am [Internet]. 1988 [cited 2017 Aug 23];259:118-25. Available from: http://www.ncbi. nlm.nih.gov/pubmed/3212438

26. Schileo E, Balistreri L, Grassi L, Cristofolini L, Taddei F. To what extent can linear finite element models of human femora predict failure under stance and fall loading configurations? J Biomech [Internet]. 2014 [cited 2015 Mar 19];47:3531-8. Available from: http://www.sciencedirect.com/science/article/pii/ S0021929014004606

27. Viceconti M, Taddei F, Cristofolini L, Martelli S, Falcinelli C, Schileo E. Are spontaneous fractures possible? An example of clinical application for personalised, multiscale neuro-musculo-skeletal modelling. J Biomech [Internet]. Elsevier; 2012 [cited 2012 Jan 3];45:421-6. Available from: http://www.ncbi.nlm.nih.gov/ pubmed/22204893

28. Bell KL, Loveridge N, Power J, Garrahan N, Stanton M, Lunt M, et al. Structure of the femoral neck in hip fracture: cortical bone loss in the inferoanterior to superoposterior axis. J Bone Miner Res [Internet]. 1999;14:111-9. Available from: http://www.ncbi.nlm. nih.gov/pubmed/9893072

29. Cristofolini L, Juszczyk M, Martelli S, Taddei F, Viceconti M. In vitro replication of spontaneous fractures of the proximal human femur. J Biomech [Internet]. Elsevier; 2007 [cited 2011 Mar 28];40: 2837-45. Available from: http://www.ncbi.nlm.nih.gov/pubmed/ 17475269

30. Martelli S, Perilli E. Time-elapsed synchrotron-light microstructural imaging of femoral neck fracture. J Mech Behav Biomed Mater [Internet]. Elsevier Ltd; 2018 [cited 2018 Jun 8];84:265-72. Available from: https://www.sciencedirect.com/science/article/pii/ S1751616118307276

31. Martelli S, Kersh ME, Pandy MG. Sensitivity of femoral strain calculations to anatomical scaling errors in musculoskeletal models of movement. J Biomech [Internet]. United States: Elsevier Ltd; 2015 [cited 2015 Sep 7];48:3615-24. Available from: http://www. ncbi.nlm.nih.gov/pubmed/26315919

32. Martelli S, Pivonka P, Ebeling PR. Femoral shaft strains during daily activities: implications for atypical femoral fractures. Clin Biomech [Internet]. 2014 [cited 2014 Aug 12];29:869-76. Available from: http://www.sciencedirect.com/science/article/pii/ S0268003314001910

33. Edwards WB, Miller RH, Derrick TR. Femoral strain during walking predicted with muscle forces from static and dynamic optimization. J Biomech [Internet]. United States: Elsevier; 2016 [cited 2017 Jan 24];49:1206-13. Available from: https://www. 
sciencedirect.com/science/article/pii/S0021929016302731?via\% 3Dihub

34. Polgár K, Gill HS, Viceconti M, Murray DW, O’Connor JJ, Polgar $\mathrm{K}$, et al. Strain distribution within the human femur due to physiological and simplified loading: finite element analysis using the muscle standardized femur model. Proc Inst Mech Eng $\mathrm{H}$ [Internet]. England; 2003 [cited 2013 Oct 6];217:173-89. Available from: http://www.ncbi.nlm.nih.gov/pubmed/12807158

35. Seo J-W, Kang D-W, Kim J-Y, Yang S-T, Kim D-H, Choi J-S, et al. Finite element analysis of the femur during stance phase of gait based on musculoskeletal model simulation. Biomed Mater Eng [Internet]. Netherlands: IOS Press; 2014 [cited 2019 Sep 26];24: 2485-93. Available from: https://content.iospress.com/articles/biomedical-materials-and-engineering/bme1062

36. Pellikaan P, Giarmatzis G, Vander Sloten J, Verschueren S, Jonkers I. Ranking of osteogenic potential of physical exercises in postmenopausal women based on femoral neck strains. PLoS One. United States: Public Library of Science; 2018;13:e0195463.

37. Anderson DE, Madigan ML. Effects of age-related differences in femoral loading and bone mineral density on strains in the proximal femur during controlled walking. J Appl Biomech [Internet]. United States: NIH Public Access; 2013 [cited 2019 Sep 26];29: 505-16. Available from: http://www.ncbi.nlm.nih.gov/pubmed/ 23185080

38. Reinbolt JA, Schutte JF, Fregly BJ, Koh BI, Haftka RT, George AD, et al. Determination of patient-specific multi-joint kinematic models through two-level optimization. J Biomech. 2005;38:621-6.

39. Lloyd DG, Besier TF, Lloyd, Besier. An EMG-driven musculoskeletal model to estimate muscle forces and knee joint moments in vivo. J Biomech. 2003;36:765-76. This is a seminal paper enabling to model variation of motor control during physical exercise.

40. Lund ME, de Zee M, Andersen MS, Rasmussen J. On validation of multibody musculoskeletal models. Proc Inst Mech Eng H [Internet]. 2012 [cited 2019 Oct 14];226:82-94. Available from: http://www.ncbi.nlm.nih.gov/pubmed/22468460

41. Bergmann G, Graichen F, Rohlmann A. Hip joint contact forces during stumbling. Langenbecks Arch Surg. 2004;389:53-9.

42. Besier TF, Lloyd DG, Ackland TR. Muscle Activation Strategies at the Knee during Running and Cutting Maneuvers. Med Sci Sport Exerc [Internet]. 2003 [cited 2019 Nov 19];35:119-27. Available from: http://www.acsm-msse.org

43. Lamberto G, Martelli S, Cappozzo A, Mazzà C. To what extent is joint and muscle mechanics predicted by musculoskeletal models sensitive to soft tissue artefacts? J Biomech [Internet]. The Authors; 2016;62:68-76. Available from: https://doi.org/10.1016/j. jbiomech.2016.07.042

44. Bergmann G, Deuretzbacher G, Heller M, Graichen F, Rohlmann A, Strauss J, et al. Hip contact forces and gait patterns from routine activities. J Biomech. 2001;34:859-71.

45. Martelli S, Valente G, Viceconti M, Taddei F. Sensitivity of a subject-specific musculoskeletal model to the uncertainties on the joint axes location. Comput Methods Biomech Biomed Engin [Internet]. 2015 [cited 2014 Jun 27];18:1555-63. Available from: http://www. ncbi.nlm.nih.gov/pubmed/24963785

46. Bailey C, Brooke-Wavell K. Optimum frequency of exercise for bone health: randomised controlled trial of a high-impact unilateral intervention. Bone [Internet]. Elsevier Inc.; 2010 [cited 2011 Nov 14];46:1043-9. Available from: http://www.ncbi.nlm.nih.gov/ pubmed/20004758

47. Bailey CA, Brooke-Wavell K. Postgraduate Symposium Exercise for optimising peak bone mass in women. 2019 [cited 2019 Oct 10]; Available from: https://doi.org/10.1017/S0029665108005971

48. Lang TF, Saeed IH, Streeper T, Carballido-Gamio J, Harnish RJ, Frassetto LA, et al. Spatial heterogeneity in the response of the proximal femur to two lower-body resistance exercise regimens. J
Bone Miner Res [Internet]. 2014 [cited 2014 Oct 13];29:1337-45. Available from: http://www.ncbi.nlm.nih.gov/pubmed/24293094

49. Ebrahim S, Thompson PW, Baskaran V, Evans K. Randomized placebo-controlled trial of brisk walking in the prevention of postmenopausal osteoporosis. Age Ageing [Internet]. 1997;26:253-60. Available from: http://www.ncbi.nlm.nih.gov/pubmed/9271287

50. Fukashiro S, Komi P V, Järvinen M, Miyashita M. In vivo Achilles tendon loading during jumping in humans. Eur J Appl Physiol Occup Physiol [Internet]. 1995 [cited 2019 Oct 14];71:453-8. Available from: http://www.ncbi.nlm.nih.gov/pubmed/8565978

51. Finni T, Ikegaw S, Lepola V, Komi P. In vivo behavior of vastus lateralis muscle during dynamic performances. Eur J Sport Sci. 2001;1:1-13.

52. Finni T, Komi P V., Lepola V. In vivo human triceps surae and quadriceps femoris muscle function in a squat jump and counter movement jump. Eur J Appl Physiol. 2000;83:416-26.

53. 53. Bergmann G, Graichen F, Rohlmann A, Bender A, Heinlein B, Duda GN, et al. Realistic loads for testing hip implants. Biomed Mater Eng [Internet]. 2010 [cited 2019 Oct 14];20:65-75. Available from: http://www.ncbi.nlm.nih.gov/pubmed/20592444

54. Aamodt A, Lund-Larsen J, Eine J, Andersen E, Benum P, Husby OS. In vivo measurements show tensile axial strain in the proximal lateral aspect of the human femur. J Orthop Res [Internet]. 1997;15:927-31. Available from: http://www.ncbi.nlm.nih.gov/pubmed/9497820

55. Morgan EF, Bayraktar HH, Keaveny TM. Trabecular bone modulus-density relationships depend on anatomic site. J Biomech. 2003;36:897-904.

56. Jee L, Rasmussen H, Caspi A, Ambler A, Broadbent JM, Cohen HJ, et al. Association of Neurocognitive and Physical Function With Gait Speed in Midlife. 2019;2:1-15.

57. 57. Lim YP, Lin Y-C, Pandy MG. Muscle function during gait is invariant to age when walking speed is controlled. Gait Posture [Internet]. 2013 [cited 2015 Apr 24];38:253-9. Available from: http://www.ncbi.nlm.nih.gov/pubmed/23267819

58. 58. Dorn TW, Schache AG, Pandy MG. Muscular strategy shift in human running: dependence of running speed on hip and ankle muscle performance. J Exp Biol [Internet]. 2012 [cited 2013 Sep 10];215:1944-56. Available from: http://www.ncbi.nlm.nih.gov/ pubmed/22573774

59. Pyka G, Lindenberger E, Charette S, Marcus R. Muscle strength and fiber adaptations to a year-long resistance training program in elderly men and women. J Gerontol [Internet]. 1994 [cited 2012 Jul 5];49:M22-27. Available from: http://geronj.oxfordjournals.org/ cgi/content/abstract/49/1/M22

60. Turner $\mathrm{CH}$, Robling AG. Designing exercise regimens to increase bone strength. Exerc Sport Sci Rev. 2003;31:45-50.

61. Turner $\mathrm{CH}$, Robling AG. Exercises for improving bone strength. $\mathrm{Br}$ J Sports Med. 2005;39:188-9.

62. Weeks BK, Beck BR. The BPAQ: a bone-specific physical activity assessment instrument. Osteoporos Int [Internet]. Springer London; 2008 [cited 2018 May 8];19:1567-77. Available from: http://link. springer.com/10.1007/s00198-008-0606-2

63. Kim S, Baker BS, Sharma-Ghimire P, Bemben DA, Bemben MG. Association between bone-specific physical activity scores and pQCTderived measures of bone strength and geometry in healthy young and middle-aged premenopausal women. Arch Osteoporos [Internet]. England: Springer London; 2018 [cited 2019 Sep 24];13:83. Available from: http://ink.springer.com/10.1007/s11657-018-0495-8

64. Dolan SH, Williams DP, Ainsworth BE, Shaw JM. Development and reproducibility of the bone loading history questionnaire. Med Sci Sports Exerc. 2006;38:1121-31.

65. Pizzolato C, Lloyd DG, Barrett RS, Cook JL, Zheng MH, Besier $\mathrm{TF}$, et al. Bioinspired technologies to connect musculoskeletal mechanobiology to the person for training and rehabilitation. Front Comput Neurosci. 2017; https://doi.org/10.3389/fncom. 2017.00096 
66. Barzan M, Modenese L, Carty CP, Maine S, Stockton CA, Sancisi $\mathrm{N}$, et al. Development and validation of subject-specific pediatric multibody knee kinematic models with ligamentous constraints. J Biomech [Internet]. 2019 [cited 2019 Sep 3];93:194-203. Available from: https://www.sciencedirect.com/science/article/pii/ S0021929019304415

67. Modenese L, Montefiori E, Wang A, Wesarg S, Viceconti M, Mazzà $\mathrm{C}$. Investigation of the dependence of joint contact forces on musculotendon parameters using a codified workflow for image-based modelling. J Biomech [Internet]. 2018 [cited 2019 Oct 14];73:108-18. Available from: http://www.ncbi.nlm.nih.gov/ pubmed/29673935

68. Martelli S, Taddei F, Testi D, Delp S, Viceconti M. NMSBuilder : an application to personalize NMS models. Proc XXIII Congr Int Soc Biomech [Internet]. July 3-7, Brussels (Belgium); 2011. p. 3-4. Available from: http://isbweb.org/images/conf/2011/ ScientificProgram/ISB2011_ScientificProgram.htm

69. Suwarganda EK, Diamond LE, Lloyd DG, Besier TF, Zhang J, Killen BA, et al. Minimal medical imaging can accurately reconstruct geometric bone models for musculoskeletal models. PLoS One 2019; https://doi.org/10.1371/journal.pone.0205628

70. Zhang J, Hislop-Jambrich J, Besier TF. Predictive statistical models of baseline variations in 3-D femoral cortex morphology. Med Eng Phys [Internet]. 2016 [cited 2019 Sep 4];38:450-7. Available from: http://www.ncbi.nlm.nih.gov/pubmed/26972387

71. Zhang J, Sorby H, Clement J, Thomas CDL, Hunter P, Nielsen P, et al. The MAP Client: User-Friendly Musculoskeletal Modelling Workflows. Springer International Publishing; 2014 [cited 2017 Feb 6]. p. 182-92. Available from: http://link.springer.com/10. 1007/978-3-319-12057-7 21

72. Bahl JS, Zhang J, Killen BA, Taylor M, Solomon LB, Arnold JB, et al. Statistical shape modelling versus linear scaling: Effects on predictions of hip joint centre location and muscle moment arms in people with hip osteoarthritis. J Biomech. Elsevier Ltd; 2019;85: 164-72.

73. Pizzolato C, Reggiani M, Saxby DJ, Ceseracciu E, Modenese L, Lloyd DG. Biofeedback for Gait Retraining Based on Real-Time Estimation of Tibiofemoral Joint Contact Forces. IEEE Trans Neural Syst Rehabil Eng [Internet]. 2017 [cited 2018 Apr 3];25: 1612-21. Available from: http://ieeexplore.ieee.org/document/ 7903736

74. Ziaeipoor H, Taylor M, Pandy M, Martelli S. A novel training-free method for real-time prediction of femoral strain. J Biomech [Internet]. Elsevier; 2019 [cited 2019 May 15];86:110-6. Available from: https://www.sciencedirect.com/science/article/pii/ S0021929019301162

75. Ziaeipoor H, Martelli S, Pandy MG, Taylor M. Efficacy and efficiency of multivariate linear regression for the rapid prediction of the femoral strain field during activity. Med Eng Phys [Internet]. 2019 [cited 2018 Dec 25];63:88-92. Available from: http://www. ncbi.nlm.nih.gov/pubmed/30551929

76. Taylor M, Perilli E, Martelli S. Development of a surrogate model based on patient weight, bone mass and geometry to predict femoral neck strains and fracture loads. J Biomech [Internet]. 2017 [cited 2017 Mar 6];55:121-7. Available from: http://www.ncbi.nlm.nih. gov/pubmed/28325584

77. Martelli S, Calvetti D, Somersalo E, Viceconti M. Stochastic modelling of muscle recruitment during activity. Interface Focus [Internet]. 2015 [cited 2015 Feb 25];5:20140094-. Available from: http://rsfs.royalsocietypublishing.org/content/5/2/20140094

78. Sartori M, Gizzi L, Lloyd DG, Farina D. A musculoskeletal model of human locomotion driven by a low dimensional set of impulsive excitation primitives. Front Comput Neurosci [Internet]. Frontiers; 2013 [cited 2014 Aug 19];7:79. Available from: http://journal. frontiersin.org/Journal/10.3389/fncom.2013.00079/abstract
79. Upadhyaya S, Lee W-S, Joslin C. Patient specific bone tracking using ultrasound for human movement analysis. 2016 IEEE Int Symp Med Meas Appl [Internet]. IEEE; 2016 [cited 2018 Oct 30]. p. 1-5. Available from: http://ieeexplore.ieee.org/document/7533738/

80. Falisse A, Serrancolí G, Dembia CL, Gillis J, Jonkers I, De Groote F. Rapid predictive simulations with complex musculoskeletal models suggest that diverse healthy and pathological human gaits can emerge from similar control strategies. J R Soc Interface. The Royal Society; 2019;16:20190402.

81. Ziaeipoor H, Taylor M, Martelli S. Population-based bone strain during physical activity: A novel procedure demonstrated for the human femur. Under Rev.

82. Scheiner S, Pivonka P, Hellmich C. Coupling systems biology with multiscale mechanics, for computer simulations of bone remodeling. Comput Methods Appl Mech Eng [Internet]. 2013 [cited 2019 Oct 1];254:181-96. Available from: https://www.google.com/ search?q=Coupling + systems + biology + with + multiscale + mechanics $\% 2 \mathrm{C}+$ for+computer+simulations+of+bone+ remodeling\&rlz=1C1GGRV_enAU756AU756\&oq=Coupling+ systems+biology+with+multiscale+mechanics $\% 2 \mathrm{C}+$ for + computer+simulations+of+bone+remodeling

83. Scheiner S, Pivonka P, Hellmich C. Poromicromechanics reveals that physiological bone strains induce osteocyte-stimulating lacunar pressure. Biomech Model Mechanobiol. Germany: Springer Verlag; 2016;15:9-28.

84. Martin M, Sansalone V, Cooper DML, Forwood MR, Pivonka P. Mechanobiological osteocyte feedback drives mechanostat regulation of bone in a multiscale computational model. Biomech Model Mechanobiol. 2019; 10.1007/s10237-019-01158-w

85. Huiskes R, Weinans H, Grootenboer HJ, Dalstra M, Fudala B, Slooff TJ. Adaptive bone-remodelling theory applied to prosthetic-design analysis. J Biomech. 1987;20:1135-50.

86. Beaupre GS, Orr TE, Carter DR. An approach for time-dependent bone modeling and remodeling-application: a preliminary remodeling simulation. J Orthop Res. 1990;8:662-70.

87. Skerry TM. Mechanical loading and bone: what sort of exercise is beneficial to the skeleton? Bone [Internet]. 1997 [cited 2019 Oct 1];20:179-81. Available from: http://www.ncbi.nlm.nih.gov/ pubmed/9071466

88. Skerry TM. One mechanostat or many? Modifications of the sitespecific response of bone to mechanical loading by nature and nurture. J. Musculoskelet. Neuronal Interact. 2006; 6:122-7

89. Lanyon LE, Rubin CT. Static vs dynamic loads as an influence on bone remodelling. J Biomech [Internet]. 1984 [cited 2019 Oct 1];17:897-905. Available from: http://www.ncbi.nlm.nih.gov/ pubmed $/ 6520138$

90. Scheiner S, Pivonka P, Smith DW, Dunstan CR, Hellmich C. Mathematical modeling of postmenopausal osteoporosis and its treatment by the anti-catabolic drug denosumab. Int $\mathrm{j}$ numer method biomed eng [Internet]. 2014 [cited 2019 Oct 1];30:1-27. Available from: http://www.ncbi.nlm.nih.gov/pubmed/24039120

91. Martínez-Reina J, Pivonka P. Effects of long-term treatment of denosumab on bone mineral density: insights from an in-silico model of bone mineralization. Bone [Internet]. 2019 [cited 2019 Oct 1];125: 87-95. Available from: http://www.ncbi.nlm.nih.gov/pubmed/ 31055117. This paper models the bone mechanobiological response to long-term denosumab treatment.

92. Trichilo S, Scheiner S, Forwood M, Cooper DML, Pivonka P. Computational model of the dual action of PTH - Application to a rat model of osteoporosis. J Theor Biol [Internet]. 2019 [cited 2019 Oct 1];473:67-79. Available from: http://www.ncbi.nlm.nih.gov/ pubmed/31009612

93. Carter DR. The relationship between in vivo strains and cortical bone remodeling. Crit Rev Biomed Eng. 1982;8:1-28.

94. Kerner J, Huiskes R, van Lenthe GH, Weinans H, van Rietbergen $\mathrm{B}$, Engh CA, et al. Correlation between pre-operative periprosthetic 
bone density and post-operative bone loss in THA can be explained by strain-adaptive remodelling. J Biomech. 1999;32:695-703.

95. Al-Dirini RMA, O'Rourke D, Huff D, Martelli S, Taylor M. Biomechanical Robustness of a Contemporary Cementless Stem to Surgical Variation in Stem Size and Position. J Biomech Eng [Internet]. 2018 [cited 2018 Dec 10];140:091007. Available from: http://www.ncbi.nlm.nih.gov/pubmed/29801163

96. Martelli S, Taddei F, Schileo E, Cristofolini L, Rushton N, Viceconti M. Biomechanical robustness of a new proximal epiphyseal hip replacement to patient variability and surgical uncertainties : A FE study. Med Eng Phys [Internet]. Institute of Physics and Engineering in Medicine; 2012 [cited 2011 Aug 10];34:161-71. Available from: http://www.ncbi.nlm.nih.gov/ pubmed/21813311

97. Martelli S, Taddei F, Cristofolini L, Gill HS, Viceconti M. Extensive risk analysis of mechanical failure for an epiphyseal hip prothesis: a combined numerical-experimental approach. Proc
Inst Mech Eng Part H J Eng Med [Internet]. Prof Eng Publishing; 2011 [cited 2011 Mar 23];225:126-40. Available from: http:// journals.pepublishing.com/openurl.asp?genre=article $\&$ id $=$ doi: 10 . 1243/09544119JEIM728

98. Martelli S, Taddei F, Cristofolini L, Schileo E, Rushton N, Viceconti M. A new hip epiphyseal prosthesis: Design revision driven by a validated numerical procedure. Med Eng Phys. Elsevier; 2011;33:1203-11.

99. Lerebours C, Buenzli PR, Scheiner S, Pivonka P. A multiscale mechanobiological model of bone remodelling predicts site-specific bone loss in the femur during osteoporosis and mechanical disuse. Biomech Model Mechanobiol. 2016;15:43-67.

Publisher's Note Springer Nature remains neutral with regard to jurisdictional claims in published maps and institutional affiliations. 